San Jose State University

From the SelectedWorks of Grinell Smith

2017

Teaching in the Age of Humans Helping Students Think about Climate Change.

Grinell Smith, San Jose State University 


\title{
ON THE HORIZON
}

\section{Teaching in the Age of Humans \\ Helping Students Think about Climate Change}

\author{
GRINELL SMITH \\ San Jose State University
}

Without significant precautions, education can equip people merely to be more effective vandals of the Earth.

-David Orr $(2004,5)$

Geologic terms are often mellifluous: abyssalplain, syncline, epoch, Flandrian transgression, Anthropocene. And for the most part, they attach to things of unimaginable antiquity and processes of stupefying graduality. Except that last one: Anthropocene. It refers to a proposed new geological epoch, distinguishable from all others by the presence of indelible marks of humanity on the earth and its geologic systems. Nobel Laureate and climate scientist Paul Crutzen, who popularized the term, explains its origin: "I was at a conference where someone said something about the Holocene. I suddenly thought this was wrong. The world has changed too much. So I said: 'No, we are in the Anthropocene.' I just made up the word on the spur of the moment. Everyone was shocked. But it seems to have stuck" (Pearce 2007, 44).

It is indeed shocking to hear that a growing number of geologistsdeliberate and contemplative as a group - think we need a new term to describe what we have wrought on the earth. It is a recognition that many of the changes scientists have documented are not transient on a human scale, an admission that we have crossed a Rubicon. As teachers, does this have import? Crutzen, along with the overwhelming majority of all other climate scientists, says it does. In that vein, David Orr (1992) argues that no priority ought to be more pressing to teachers than educating toward ecological literacy, and many of the world's leading scientists and thinkers consider the 
threat of climate change to be the most significant long-term existential threat we face (Mainau 2015). Considering this thesis requires two things at least: a basic understanding of climate science and an appreciation of how education can frame one's thinking about what it means to be a human living in the Anthropocene. I know of no better way to embark on this exploration than to begin with my daughter.

Last year my family spent the summer in a Mexican fishing village about a hundred kilometers north of Puerto Vallarta. My seven-year-old daughter and I were walking to town for lunch one day when she saw a flyer with a picture of a sea turtle hatchling on it stapled to a tree trunk. It was an Olive Ridley, an endangered species endemic to the area whose numbers have been in decline in recent years, in part because many of the locals consider their eggs a delicacy. In the picture, a child held it aloft, finger on one side, thumb on the other, like you would hold a piece of sushi. The caption said, "Hatchling Release: Tonight at Sunset!" Our evening plans crystalized instantly.

We made our way to the beach a bit before sunset, and my daughter joined the 20 or so Mexican children gathered around a Rubbermaid bin full of palm-sized hatchlings, greenish-gray and utterly artificial-looking, like animated clay models. The children jostled each other for a spot around the bin and grabbed at turtles as I resisted the urge to rush in and hold my hands underneath. The sun inched toward the horizon, and a local teacher arrived to sort out the chaos. She made a line in the sand about 25 meters from the ocean and stationed the kids behind it, and then she gave each of them a squirming hatchling. She explained that it does not work just to put the hatchlings in the water; they need to make the trip across the beach on their own, because if they do not struggle beforehand, they will not be ready to swim. She said that after many decades, the survivors would return to this very beach to lay eggs. She asked the children to think of names for their turtlesmy daughter's became Jillie - and to wish them well. Then she counted to three, and the children put all the hatchlings down on the sand.

Like a fleet of robots, the hatchlings paddled and lurched automatically toward the ocean as we yelled and shouted, and after about 10 minutes, the first one made it in. A big wave rolled forward, covered him over, and when it receded, he was gone. A cheer rose into the air. Others made it to the water only to be washed up on the sand again by the powerful surf. The toddler beside my daughter, unable to contain himself any longer in the face of his turtle's slow progress, escaped his mother's grip and waddled out to help, very nearly crushing Jillie like a walnut as my daughter and I sat dumbstruck, before his mother rushed forward and lifted him into the air by the straps of his overalls. Disaster narrowly averted. We all settled in be- 
hind the line again, cheering and watching as the orange sky darkened. One after another as we shouted their new names, the hatchlings reached the ocean. I tried to keep my mind off the odds: of the 20 Olive Ridleys the children released, two - maybe three - will survive the decades at sea to return. Perhaps fewer. Perhaps none.

Olive Ridley sea turtles are ancient compared to humans. They belong to a family of animals that appeared on Earth 110 million years ago, an impossibly long time. Long enough for the continents, which move as fast as fingernails grow, to travel the globe. Sea turtles were around when Mount Everest was a seafloor basin. Anatomically modern humans, on the other hand, made the scene a mere 200,000 years ago. It was not until about 50,000 years ago that humans had become behaviorally modern. By then, they were painting caves and using tools and language; they had created culture, mastered fire.

So, for 50,000 years, people just like us lived and died, loved and lost, and left their marks on the world, which, despite all that human living and dying, loving and losing, remained relatively unchanged. Then, 250 years ago, James Watt invented a miracle: the rotary steam engine, which made the first factories possible. Eighty years later, Nicklaus Otto developed the internal combustion engine, and in 1885 Karl Benz put one into the world's first automobile. By 1920, Henry Ford was building 3,000 cars a day, realizing his pipe dream of a car in every driveway sometime around 1950 by one measure, the year the number of cars in America surpassed the number of homes in America.

I recount this abbreviated history of our species for one reason: to call attention to the unprecedented swiftness of recent changes in the way humans live. For 200,000 years humans have walked the Earth, and until 250 years ago nobody ever worked in a factory, or bought a manufactured good, or drove anywhere; nobody burned a fossil fuel to power an electric light or ate anything that wasn't local. Now almost all of us do. And in so doing, we have changed the composition of Earth's atmosphere in a terrifyingand unprecedented - way. This is the Anthropocene, the age of humans.

It is worth considering some climate science basics that, because of their importance, should be familiar to us all: four pictures. First, figure 1, the Keeling Curve, named after Charles David Keeling who in 1958 began measuring the amount of carbon dioxide, $\mathrm{CO}_{2}$, in the atmosphere. Why $\mathrm{CO}_{2}$ ? Because when you burn fossil fuel to power your car, $\mathrm{CO}_{2}$ comes along for the ride, 19 pounds of it for every gallon of gas you burn, 5 tons a year if you are an average driver. Because two-thirds of the nation's electricity is generated by fossil fuel-fired power plants, and for every kilowatt hour of electricity they generate, they also make about 2 pounds of $\mathrm{CO}_{2}$. The Kee- 


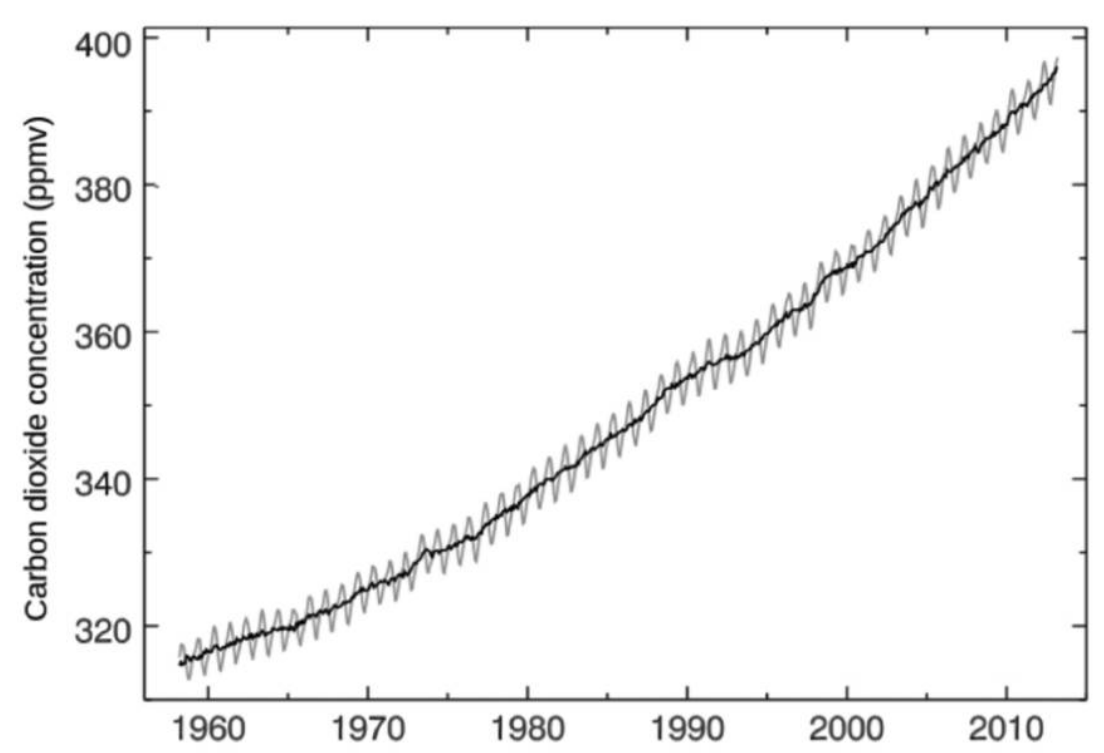

Fig. 1. Atmospheric carbon dioxide $\left(\mathrm{CO}_{2}\right)$ since 1958, measured at Mauna Loa Observatory in parts per million by volume (ppmv). Source: Adapted from Wikimedia Commons. Data available from the Scripps Institute (https://scripps.ucsd.edu/programs/keelingcurve/).

ling Curve is a picture of where that tonnage of $\mathrm{CO}_{2}$ goes. It is a simple picture with an obvious point: atmospheric $\mathrm{CO}_{2}$ is increasing. For 10,000 years before the industrial revolution, atmospheric $\mathrm{CO}_{2}$ concentration was about 280 parts per million (ppm). By 1958, when Keeling started measuring, it was $310 \mathrm{ppm}$. Today, it's over $400 \mathrm{ppm}$. The added $\mathrm{CO}_{2}$ is from human activity. We are the cause.

Figure 2, atmospheric $\mathrm{CO}_{2}$ levels over the last 400,000 years-twice as long as humans have been around-puts Keeling's numbers into perspective and brings the lie to the adage "There's nothing new under the sun." This is new. The Keeling Curve is, of course, subsumed in this longer time frame graph: it is the steep spike, far right, that ends at the current level. This graph shows that current atmospheric $\mathrm{CO}_{2}$ concentration is far higher than it has been since humans first appeared on Earth. In fact, mounting evidence shows that it is higher than it has been at any time during the past 2 million years (Soloman et al. 2007). And, again, just to be clear, we are the cause.

Figure 3 reveals why the first two figures matter: overlay the average global temperature on the $\mathrm{CO}_{2}$ concentration graph for the last 400,000 years, and you find that they travel together. That's because $\mathrm{CO}_{2}$ traps heat, like glass in a greenhouse: less $\mathrm{CO}_{2}$, cooler climate; more $\mathrm{CO}_{2}$, warmer climate. 


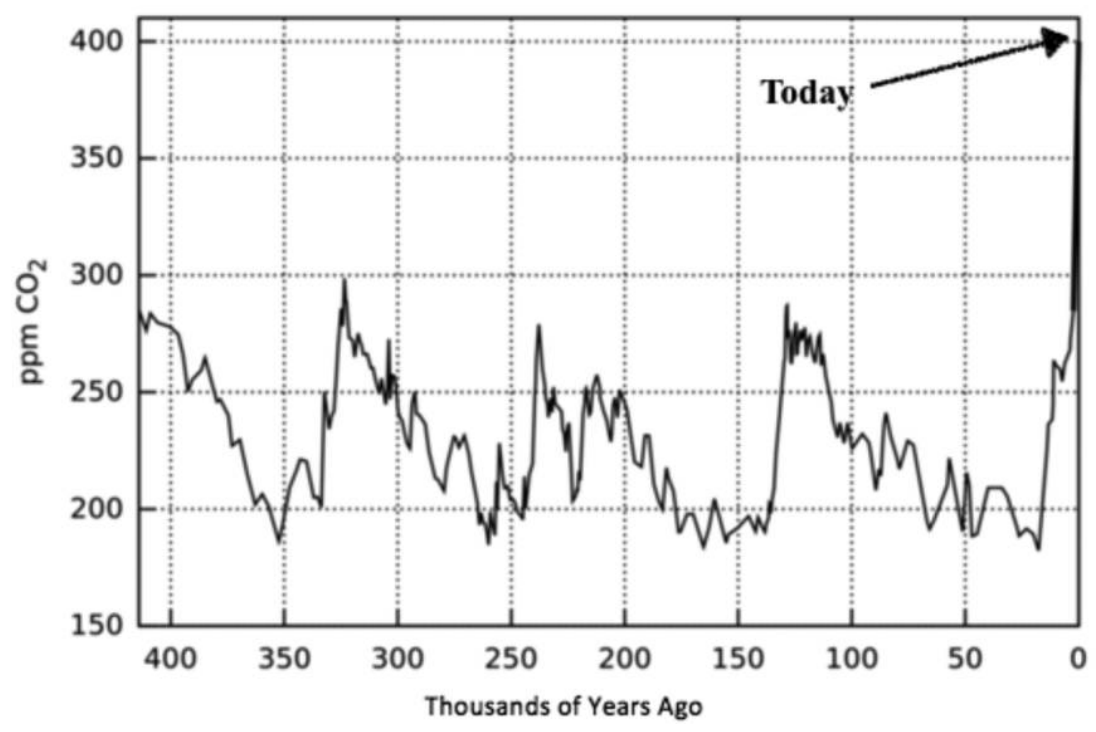

Fig. 2. Concentrations of atmospheric $\mathrm{CO}_{2}$ over the past 400,000 years from the Vostok, Antarctica, Ice Core. Source: Adapted from Skepticalscience.com. Data available from the US Department of Energy's Carbon Dioxide Information Analysis Center (http://cdiac.ornl.gov/).

Now, figure 4, the one that pertains most directly to those sea turtle hatchlings and the children who set them free: projections of future global temperature. The four lines represent projections under four different emis-
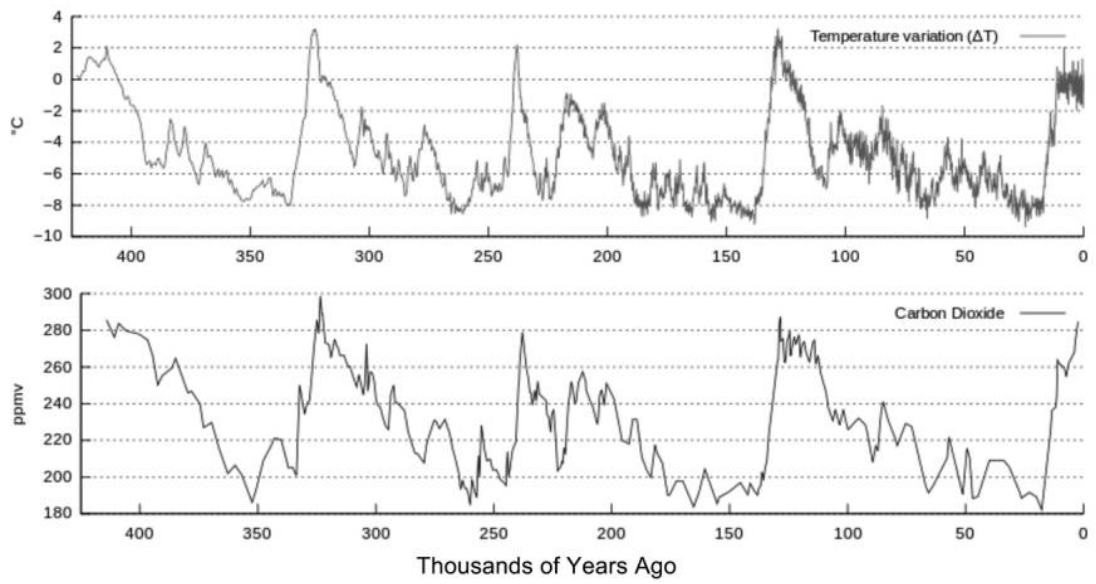

Fig. 3. Top graph: variation in global temperature over the past 400,000 years. Bottom graph: variation in global $\mathrm{CO}_{2}$ concentration over the past 400,000 years. Source: Adapted from Wikimedia commons. Data available from the US Department of Energy's Carbon Dioxide Information Analysis Center (http://cdiac.ornl.gov/). 


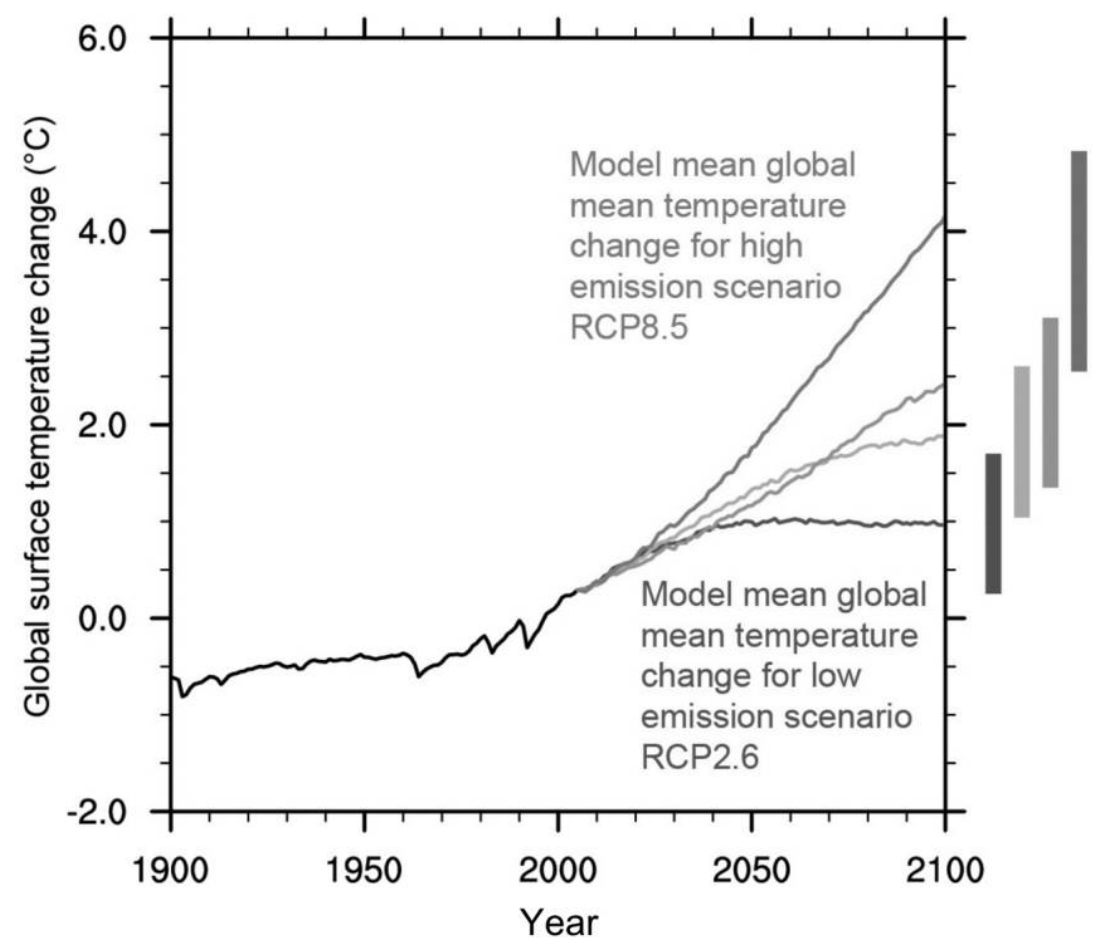

Fig. 4. Projections of global surface temperature change under four different representative emissions concentration pathways (RCPs). The top line shows a high emission scenario and the bottom line shows a low emission scenario. The vertical bars to the right show likely temperature ranges by the year 2100. Source: US Environmental Protection Agency.

sions scenarios. The bottom line in the graph represents the best-case scenario, what is likely to happen to global temperature if all goes as well as it can: we control $\mathrm{CO}_{2}$ emissions, develop alternative energy sources, and get lucky with the consequences that are already too late to dodge: Earth gets a degree or so warmer over the next century. We have already locked in at least that much warming. The top line represents the worst case: we continue to emit $\mathrm{CO}_{2}$ at high levels, and consequences unfold at the top end of the current range of estimates: Earth gets $4^{\circ} \mathrm{C}$ warmer.

Now is when most people will say something like, "Four degrees celsius warmer? Big deal. I'll wear shorts," because most people conflate weather and climate. Here's the difference: with weather in most parts of the world, the temperature swings far more than $4^{\circ} \mathrm{C}$ every day; in contrast, when the world's climate was $4^{\circ} \mathrm{C}$ cooler than it is today, half of North America was under an ice sheet nearly a mile thick. (This is not hyperbole, by the way; it 
is a geologic fact.) So what would $4^{\circ} \mathrm{C}$ warmer look like? Superlatives fail utterly. It is safe to say you would not recognize the place. Change is coming. Maybe change far outside the parameters of anything civilization has yet faced. It is coming swiftly. And again, just to be clear, we are the cause.

I should note that these four figures represent the overwhelming consensus views of the scientific community. While they are frequently dismissed or diminished in partisan arenas where mainstream science does not hold sway, scientifically they are not controversial in the least (Cook et al. 2016). They are scientifically established (Pachauri et al. 2014). And now is when it should occur to you that the subject of climate change is more than just ecological. It is also political, economic, social, and cultural. And if we have any hope at all of escaping the looming horror show of consequences we are headed for, the problem is also educational. In 1949, Aldo Leopold wrote, "One of the penalties of an ecological education is that one lives alone in a world of wounds. Much of the damage inflicted on land is quite invisible to laymen. An ecologist must either harden his shell and make believe that the consequences of science are none of his business, or he must be the doctor who sees the marks of death in a community that believes itself well and does not want to be told otherwise" $(1970,166)$. Five decades on, and the extent to which the damage is still invisible to laymen is a failure of education. That a problem of this magnitude and urgency can so readily escape the public's attention is a failure of education. As others have noted, the previous generation might legitimately claim they did not know enough to prevent climate change; our generation can only pretend to make that claim.

As teachers, what should we do? Orr (2004) directs us to clarify our purposes in response to his question, what is education for? He asks us to think deeply, to think long-term, and to connect the choices we make to who we are not just as teachers but as ethical and moral beings. I, for one, can think of no moral or ethical reason to ignore what we know about climate change and its likely consequences, or to fail to teach it to my students. Nor can I think of a sound pedagogical reason either. It should pervade. In science education, the connections are obvious, and they are now explicitly addressed in the Next Generation Science Standards (NGSS). But there is fodder for other subject areas as well, canonized in the Common Core. In math, students might explore the mountains of climate data scientists have produced, learn to understand the graphs, probe how variables are related. In history and social studies, students might learn about events and trends that have brought us to this crossroads. In language studies, students might examine the texts and narratives we use to explain, to understand, to justify; students 
might consider the forces at work in a species so noble in reason, and in apprehension so like a god, and yet so capable of feckless destruction. Schoolwide, we might explore what it means to foster an essential feature shared by the most successful learning communities: that their members care for each other.

Specifically, what is needed is a way to support discourse about climate change in which scientific conclusions can become meaningful even to those who are not just merely uninformed about the science but who actively resist what scientists tell us is true. In short, what is needed is a way to close the very large gap between what scientists know about climate change ( $-97 \%$ of climate scientists believe in anthropogenic climate change) and what the general public thinks they know (less than one in 10 Americans correctly estimates the strength of that assessment; Cook et al. 2016). This so-called consensus gap is largely the result of well-organized misinformation campaigns that seek to undermine policies aimed at reducing carbon emissions by transforming public discourse about climate change into a highly charged ideological debate (McCright and Dunlap 2011; Oreskes and Conway 2011). Bridging the gap has proven to be very hard. Psychologists, scientists, ethicists, and communications experts point to several features of climate change science that misinformation campaigns exploit and that make it difficult to engage with (see, e.g., Markowitz and Shariff 2012; Swim et al. 2011). First, climate systems are nonlinear and exceedingly complex, which means that intuition is a dull tool for the job of understanding climate change. Second, the effects of climate change play out in global systems, yet they follow from local actions we do not readily interpret as harmful. This creates conceptual distance between one's actions and their untoward effects, making it difficult to think of those actions as imbued with moral or ethical import. Third, the future effects of climate change are uncertain, which, in addition to conceptual distance, gives rise to a spatial and temporal distance between actions and consequences that makes unrealistic optimism easier than it ought to be. The result of the interplay of these features in a partisan context is that climate change discussions often engender an us-versus-them tribalism that calls for adherence to one's positions even if it means rejecting vetted facts and expert opinion out of hand.

In light of these known challenges, I offer four specific recommendations for teachers engaged in climate change education. Each of these recommendations addresses one or more of the above challenges by taking into account the psychology at work at its root and mapping that psychology to pedagogy: (1) establish a learning community that works to disrupt in-group favoritism; (2) help students identify a set of superordinate goals everyone can 
agree to pursue; (3) structure discursive patterns toward deliberation rather than dispute; and (4) help students concretize their beliefs in terms of realor realistically and reasonably imagined - people, places, and events.

Teachers might conceive of these recommendations as a stepwise approach. The third recommendation - leveraging discourse wisely - is the linchpin, but is not easily accomplished without first building a cohesive and caring learning community (the goal of the first two recommendations) and is unlikely to change anyone's thinking or behavior without opportunities to move from the general to the particular (the goal of the last recommendation).

\section{Building Inclusive Learning Communities to Reduce In-Group Favoritism and Attribution Bias}

Humans seek out association relentlessly; we are a clannish lot. We aggregate along any and every available line of difference: linguistic, religious, racial, geographical, political, ideological. So loath are we to remain unaffiliated that in the absence of obvious signifiers of difference, we make them up: Ford versus Chevy, PC versus Mac, Hatfield versus McCoy. We're like Sneeches. As Jane Howard $(1998,234)$ observed, "Call it a clan, call it a network, call it a tribe, call it a family. Whatever you call it, whoever you are, you need one." This happens in classrooms as well, obviously enough, and constitutes one of the most persistent and enduring challenges teachers face. Without dedicated effort to prevent it, lines are drawn and alliances form, cliques throw their weight around with caprice; turn your back for long, and it is Lord of the Flies.

The trouble with group affiliation is that it influences how we perceive the beliefs and actions of others. We are far more likely to attribute the good things in-group members do to their admirable dispositions while forgiving the bad things as reasonable, or at least understandable, responses to the situations they are in. Conversely, we are likely to interpret grudgingly the good things out-group members do as "mere" responses to a given situation, while attributing the bad things they do to their dispositions; they are "a basket of deplorables"; she is "a nasty woman." This asymmetry of attribution, what psychologists refer to as attribution bias, matters because when you attribute words and behavior to someone's disposition rather than the situation they happen to be in, their words and behavior are easier to ignore or reject. From your position across a partisan divide, the ideas and behavior of those with whom you disagree more readily become the ideas of madmen, the opinions of liars, the actions of idiots. Attribution bias is of particular 
concern to climate change educators because beliefs and attitudes about climate change are partisan: liberals are more likely to believe in and be concerned about anthropomorphic climate change than conservatives (Kahan et al. 2012).

Nel Noddings's (2015) conception of an ethic of care offers teachers a way to mitigate against the challenges to learning that can result from this human tendency to choose sides. In Noddings's conception, caring is a relational interplay between the one-caring and the cared-for characterized by three features. First, to care for another requires engrossment in an other's concerns that goes deep enough to allow a robust understanding not only of who the other is and what she is about but also something about the situation she finds herself in. This opens the possibility for the second feature, motivational displacement, which can enable the one-caring to act on behalf and from the perspective of the cared-for. And when the cared-for recognizes and interprets the action of another as underpinned by positive inclinations, the loop closes: ethical caring exists. Teachers might look to Watson and Eckens's (2003) "Learning to Trust" for guidance in building and supporting caring classroom communities with an ethic of care at the center, and to Rabin and Smith's (2013) "Teaching Care Ethics: Conceptual Understandings and Stories for Learning," as well as Rabin's (2014) "Don't Throw the Rocks! Cultivating Care with a Pedagogy called Rocksin-the-Basket" for guidance on how to help students adopt an ethic of care consistent with such classroom communities.

\section{Identifying Superordinate Goals to Reduce Intergroup Conflict}

In discussions about anything as complex and uncertain as climate change, legitimate differences of opinion are bound to exist; indeed, they often become the nexus of much learning. When classmates find themselves on opposite sides of an issue, sociologists have long recognized the utility of superordinate goals - goals too large for one group to accomplish by themselvesto keep differences of opinion from becoming fault lines along which a class fractures. In a classic experimental display of the power of superordinate goals to influence group behavior, in 1961, sociologist Muzafar Sherif recruited 22 pre-teen boys to a summer camp in Robber's Cave State Park, Oklahoma. He assigned each boy either to the Rattlers or the Eagles and set them up in cabins on opposite sides of the park. After a week of in-group bonding, he pitted the Rattlers and Eagles against each other in a series of competitions. Perhaps not surprisingly, intergroup conflict erupted, and the more contact between the two groups, the more severe the conflict became. 
Taunting and name calling quickly escalated to physical confrontations. The Rattlers burned the Eagles's flag. In retaliation, the Eagles ransacked the Rattlers' camp. Intergroup conflict remained high even after researchers enforced a cooling off period, and it did not subside until Sherif provided superordinate goals - he tasked the boys with challenges that required cooperation and coordinated activity to reach a goal neither group could reach alone.

The lesson here for teachers is to help students define and articulate a set of commonly held goals. Again, Watson and Eckens's (2003) "Learning to Trust" showcases how to build and maintain an inclusive learning community that remains oriented to commonly held goals by articulating agreedupon values and developing norms and behavioral expectations in collaboration with one another. In the context of climate change, developing superordinate goals might begin with asking students to identify common values and beliefs about the health of ecosystems, human systems, and the interplay between the two that intersect with the subject of climate change in broad ways but do not necessarily relate directly (e.g., "We agree that living things have a right to exist and that people may need to act to ensure that right is preserved" or "We believe everyone has the right to life, liberty, and the pursuit of happiness, and these rights extend to future generations"). Once articulated and agreed on, these larger goals can become touchstones to help keep students functioning as a group even as they engage in deliberating across difference.

\section{Framing Discourse Carefully to Reduce Confirmation Bias}

With topics that are not overly politically or socially charged, there is utility in helping students engage in discourse generally and argumentation in particular. In framing and supporting an argument, students become facile with both content and context, and their learning is deeper for it (see, e.g., Kuhn et al. 2010). This idea is reflected in both the Next Generation Science Standards (NGSS) and the Common Core's increased focus on discourse and argument. But argumentation comes in two distinct flavors, deliberation and dispute, and while both seem to help people learn content, deliberation is better suited to helping students consider more deeply the concerns of both sides of an argument. Dispute, on the other hand, can result in entrenching students' previously held opinions, making it more difficult to entertain opposing positions (Felton et al. 2009). The reason is straightforward: the goal of deliberation is to reach consensus, while the goal of dispute is to win. Thus, while deliberation fosters community by asking stu- 
dents to explore difference as a way to map the landscape of commonality, dispute is a zero-sum game, and in every zero-sum game with a winner, there is also a loser. And nobody likes to lose.

Framing argumentation toward deliberation and away from dispute takes careful thought. A typical approach leading to dispute might involve a teacher asking students to consider several courses of action related to the threat of climate change and then assigning debate teams to defend a particular course of action against other possibilities. In this disputative approach, students seek to win by championing a particular action; to the extent that thinking about other alternatives is done at all, it is in the service of undermining them. This opens the door for confirmation bias, a pernicious error of thinking in which people pay closer attention to information that supports a predetermined position than information that would undermine it. Instead of dispute, a teacher might task groups or individuals with using scientific evidence to explicate the pros and cons of each of a number of possible actions, with the goal of preparing an objective set of ranked recommendations. In this scenario, the threat of "losing" a debate does not exist, and so it becomes less threatening to authentically entertain and explore the merits of a range of actions, and thus the likelihood of confirmation bias is reduced.

A key insight for teachers interested in fostering deliberation rather than dispute comes from the observation that the bulk of most people's argumentation experience comes from disputative interpersonal conflict in which deliberation is not the norm. To address this, teachers should be explicit about discourse goals, and they should expect that their students will need guidance (Felton et al. 2009; Felton and Kuhn 2001). This is particularly important with regard to climate change education, in which the "default" discourse pattern of dispute is likely to spark underlying partisanship, adding the threat of attribution bias to the danger of confirmation bias. In such a dispute, scientifically vetted facts, findings, and predictions will not hold sway like they might in other arenas; instead, a person may take a position based on his or her membership in a particular sociopolitical group as a tactic to win a zero-sum game rather than from any deep understanding or analysis of the science involved.

\section{Using Real or Realistically Imagined People, Places, and Events to Help Students Think in Concrete Ways}

Teachers often bemoan the fact that their students do not seem readily to connect classroom learning to their larger lives. Psychologists agree. In a series of experiments about how people make use of information about the 
behavior of others, psychologists Richard Nisbett and Eugene Bordiga found time and time again that people are not good at using general, or baseline, information about behavior to predict what they themselves might do in specific circumstances. They also documented the converse: people often unpacked scenarios about the behavior of individuals as generalities. As they put it, "Subjects' unwillingness to deduce the particular from the general was matched only by their willingness to infer the general from the particular" $(1975,939)$. This suggests a teaching strategy to help students bridge the conceptual, temporal, and spatial distance separating individual beliefs and actions and their consequences: use what I call the "proper noun" approach. Rather than thinking generally about how climate change threatens populations in coastal areas, students might learn about a Bangladeshi woman named Jahanara Khatun, who lost her home from a cyclone, lost her husband in the aftermath, and "became so destitute that she sold her son and daughter into bonded servitude" (Harris 2014). Rather than posit the decontextualized and overly simplistic "Coal miners will just have to find new jobs," students might think about what that position meant for John McCall, who lost his job in a McDowell County, West Virginia, coal mine and "got caught up in the dark undertow of drugs that defines life for so many here in McDowell County, almost died of an overdose in 2007, and now lives on disability payments" (Gabriel 2014). In the face of the kinds of specifics that attach to proper nouns, students are less likely to fail to connect the positions they support to the cost they may exact on people and the environment.

Of course, this "proper noun" approach is likely to sharpen the edge on the overwhelming sense of despair, anxiety, even anger, that often affects students deeply as they confront the causes and consequences of climate change. Finding a way to help them navigate these feelings that isn't dismissive or cartoonish but that does not go racing off toward nihilism is no small task. Two observations might be of use here. First, a refusal to face things simply because they may be terrible to contemplate does not change how terrible they are. In fact, with climate change, such a refusal may well make these things worse. The moral and ethical duty this suggests is compelling enough for some. And then there is this: we are all in it together. Solidarity, combined with even a dash of hope, is a powerful weapon against despair. To me, this is the most compelling reason to teach my students about climate change: I care about my daughter, who sent Jillie into the sea with such uninformed hope. I feel an obligation to preserve that hope, despite the presence of so much information that points toward ecological collapse. And I care about your daughters and sons, too. In the face of a changing climate, alarming rates of species loss, ever-increasing rates of consumption of non- 
renewable fossil fuels, and the passing of one tipping-point after another, it is difficult to maintain optimism for the future health of the ecosystem. It is not, however, difficult to maintain hope. I began this essay with a quote from Orr. I close with another. Describing the difference between optimism and hope, he writes, "Optimists know the odds are in their favor; hope is the faith that things will work out whatever the odds. Hope is a verb with its sleeves rolled up. Hopeful people are actively engaged in defying or changing the odd" (Orr 2009, 182). I am with Orr; I believe teaching is about changing the odds. Teaching is a job with its sleeves rolled up.

\section{References}

Cook, John, Naomi Oreskes, Peter T. Doran, William R. L. Anderegg, Bart Verheggen, Ed W. Maibach, J. Stuart Carlton, Stephan Lewandowsky, Andrew G. Skuce, Sara A. Green, Dana Nuccitelli, Peter Jacobs, Mark Richardson, Barbel Winkler, Rob Painting, and Ken Rice. 2016. "Consensus on Consensus: A Synthesis of Consensus Estimates on Human-Caused Global Warming." Environmental Research Letters 11 (4): 048002.

Felton, Mark, Merce Garcia-Mila, and Sandra Gilabert. 2009. "Deliberation versus Dispute: The Impact of Argumentative Discourse Goals on Learning and Reasoning in the Science Classroom." Informal Looic 29 (4): 417-46.

Felton, Mark, and Deanna Kuhn. 2001. "The Development of Argumentive Discourse Skill." Discourse Processes 32 (2-3): 135-53.

Gabriel, Trip. 2014. "50 Years into the War on Poverty, Hardship Hits Back." New York Times, April 20. https://www.nytimes.com/2014/04/21 /us/50-years-into-the-war-on-poverty-hardship-hits-back.html?_r $=0$.

Harris, Gardiner. 2014. "Borrowed Time on Disappearing Land." New York Times, March, 28. https://www.nytimes.com/2014/03/29/world/asia/facing -rising-seas-bangladesh-confronts-the-consequences-of-climate-change.html.

Howard, Jane. 1998. Families. Piscataway, NJ: Transaction.

Kahan, Dan M., Ellen Peters, Maggie Wittlin, Paul Slovic, Lisa Larrimore Ouellette, Donald Braman, and Gregory Mandel. 2012. "The Polarizing Impact of Science Literacy and Numeracy on Perceived Climate Change Risks." Nature Climate Chanoe 2 (10): 732-35.

Kuhn, Deanna, Yanan Wang, and Huamei Li. 2010. "Why Argue? Developing Understanding of the Purposes and Values of Argumentive Discourse." Discourse Processes 48 (1): 26-49. 
Leopold, Aldo. 1970. A Sand County Almanac: With Other Essays on Conservation from Round River. New York: Ballantine.

Mainau Declaration on Climate Change. 2015. http://www.mainaudeclaration .org/home.

Markowitz, Ezra M., and Azim F. Shariff. 2012. "Climate Change and Moral Judgment." Nature Climate Chanoe 2 (4): 243-47.

McCright, Aaron M., and Riley E. Dunlap. 2011. "The Politicization of Climate Change and Polarization in the American Public's Views of Global Warming, 2001-2010.” Sociological Ouarterly 52 (2): 155-94.

Nisbett, Richard E., and Eugene Borgida. 1975. "Attribution and the Psychology of Prediction." Iournal of Personality and Social Psychology 32 (5): 932-43.

Noddings, Nel. 2015. The Challenge to Care in Schools. 2nd ed. New York: Teachers College Press.

Oreskes, Naomi, and Erik M. Conway. 2011. Merchants of Doubt: How a Handful of Scientists Obscured the Truth on Issues from Tobacco Smoke to Global Warming. New York: Bloomsbury.

Orr, David W. 1992. Ecological Literacy: Education and the Transition to a Postmodern World. Albany, NY: SUNY Press.

Orr, David W. 2004. Earth in Mind: On Education, Environment, and the Human Prospect. London: Island.

Orr, David W. 2009. Down to the Wire: Confronting Climate Collapse. Oxford: Oxford University Press.

Pachauri, Rajendra K., Myles R. Allen, V. R. Barros, J. Broome, W. Cramer, R. Christ, and J. A. Church et al. 2014. Climate Change 2014: Synthesis Report; Contribution of Working Groups I, II and III to the Fifth Assessment Report (AR5) of the Intergovernmental Panel on Climate Change (IPCC). Geneva: IPCC.

Pearce, Fred. 2007. With Speed and Violence: Why Scientists Fear Tipping Points in Climate Change. Boston: Beacon.

Rabin, Colette. 2014. "Don't Throw the Rocks! Cultivating Care with a Pedagogy Called Rocks-in-the-Basket." Iournal of Research in Childhood Education 28 (2): 145-61.

Rabin, Colette, and Grinell Smith. 2013. "Teaching Care Ethics: Conceptual Understandings and Stories for Learning." Iournal of Moral Education 42 (2): 164-76.

Solomon, Susan, Dahe Qin, Martin Manning, Z. Chen, M. Marquis, K. B. Averyt, M. Tignor, and H. L. Miller. 2007. Contribution of Working Group I to the Fourth Assessment Report of the Intergovernmental Panel on Climate Change, 2007. Cambridge: Cambridge University Press. 
Swim, Janet K., Paul C. Stern, Thomas J. Doherty, Susan Clayton, Joseph P. Reser, Elke U. Weber, Robert Gifford, and George S. Howard. 2011. "Psychology's Contributions to Understanding and Addressing Global Climate Change." American Psychologist 66 (4): 241-50.

Watson, Marilyn, and Laura Ecken. 2003. Learning to Trust: Transforming Difficult Elementary Classrooms Through Developmental Discipline. Hoboken, NJ: Jossey-Bass. 